\title{
Molecular diversity, phylogeography and genetic relationships of the Silene paradoxa group of section Siphonomorpha (Caryophyllaceae)
}

\author{
Marianne Leuzinger • Yamama Naciri • \\ Pierre-Emmanuel Du Pasquier · Daniel Jeanmonod
}

Received: 7 March 2013/Accepted: 21 April 2014/Published online: 30 May 2014

(C) Springer-Verlag Wien 2014

\begin{abstract}
We investigate the genetic diversity and demographic patterns of the Silene paradoxa group from section Siphonomorpha, which includes the three species $S$. paradoxa, S. fruticosa and S. aristidis. Eight additional taxa, belonging to the same section, were also included in this study for comparative purposes: S. nutans, S. viridiflora and six species of the italica complex. The nuclear internal transcribed spacer (ITS) and the two chloroplast spacers $t r n \mathrm{H}-p s b \mathrm{~A}$ and $t r n \mathrm{~S}-t r n \mathrm{G}$ show that the paradoxa group constitutes a separate genetic lineage within section Siphonomorpha and includes three well-differentiated species, characterized by different levels of genetic diversity and demographic histories. All three species showed specific haplotypes and ITS variants, intraspecific variation and contrasting demographic histories. S. paradoxa probably followed a demographic expansion scenario, whereas $S$. fruticosa and S. aristidis most likely went through spatial expansions in the past. Chasmophyte species and species from open rocky habitats are found in both the paradoxa group and the italica complex, suggesting that the switch
\end{abstract}

Electronic supplementary material The online version of this article (doi:10.1007/s00606-014-1071-3) contains supplementary material, which is available to authorized users.

M. Leuzinger · Y. Naciri ( $₫)$ · P.-E. Du Pasquier .

D. Jeanmonod

Unité de Phylogénie et Génétique Moléculaires, Conservatoire et Jardin botaniques, 1292 Chambésy, Geneva, Switzerland

e-mail: Yamama.Naciri@ville-ge.ch

M. Leuzinger

Institute of Integrative Biology, ETH Zurich, 8092 Zurich, Switzerland

Y. Naciri · P.-E. Du Pasquier · D. Jeanmonod Laboratoire de Systématique Végétale et Biodiversité, University of Geneva, 1292 Chambésy, Geneva, Switzerland between the chasmophytic and open habitats occurred at least twice in the Siphonomorpha section.

Keywords ITS - Silene aristidis - Silene fruticosa .

Speciation $\cdot \operatorname{trn} \mathrm{H}-p s b \mathrm{~A} \cdot \operatorname{trn} \mathrm{S}-t r n \mathrm{G} \cdot$ Demographic history

\section{Introduction}

Species description has predominantly relied on morphological characteristics and ecological traits, with different, and sometimes diverging, species concepts used across and within kingdoms. The use of molecular markers over recent decades has increased the number of independent characters that can be used in taxonomy and systematics. However, the increasing use of molecular markers in systematic studies has also highlighted other issues that can be encountered when delineating species (de Queiroz 2007). One of these is to assess whether the described morphospecies can also be circumscribed at the molecular level by the presence of specific DNA sequences. A perfect match in species delineation between DNA sequences and morphometric characters is expected when species are old enough for new mutations to have accumulated since the speciation event, and for complete lineage sorting to have been achieved, with no subsequent gene flow between the new species. In this case, the morphospecies would fit the phylogenetic species concept where conspecific sequences group together as an entity separated from sequences from all other species.

The present study aims at testing the validity of morphospecies at the molecular level in a group of Silene species, the paradoxa group, which belongs to section $\mathrm{Si}$ phonomorpha, as accepted by Chater et al. (1993) and Jeanmonod and Mascherpa (1982). This section comprises 
about 35 species distributed across the entire Mediterranean region and is well characterized morphologically by pyramidal inflorescences, persisting caudical leaves and rosettes as well as cylindrical-clavate calyces (Chowdhuri 1957; Jeanmonod and Mascherpa 1982). All species are diploid with $2 n=24$ chromosomes, and they are mostly perennial and rarely biennial (S. gigantea L., S. nemoralis Waldst. \& Kit. and S. splendens Boiss.). Nine species of section Siphonomorpha were included in the latest published phylogeny of Caryophyllaceae based on ITS and five chloroplast loci (Greenberg and Donoghue 2011). Genetic relationships among these nine species, as well as the relationship of section Siphonomorpha with other sections, were unresolved (Greenberg and Donoghue 2011), despite their clear morphological characterization (Chowdhuri 1957; Jeanmonod and Mascherpa 1982). The Western and the widespread Mediterranean species of section Siphonomorpha were revised using morphological and ecological characteristics by Jeanmonod (1985a, b), who distinguished four entities of unequal sizes: the paradoxa group, the italica complex, and two independent species: S. viridiflora L. and S. nutans L.

The paradoxa group comprises $S$. paradoxa L. and three species growing in rock crevices called chasmophytes: $S$. aristidis Pomel, S. fruticosa L., and S. sessionis Batt. Silene paradoxa is the most widespread species in the paradoxa group with a large continental distribution ranging across south-eastern France, Corsica, Italy, Sicily, former Yugoslavia and north-western to central Greece (Jalas and Suominen 1986; Greuter 1997). It grows on both siliceous and calcareous substrates and is a facultative metallophyte, displaying heavy-metal tolerance in some populations (Mengoni et al. 2001). Silene fruticosa has a fragmented distribution along the Mediterranean coast in Sicily, Malta, southern Greece, Karpathos, Kassos and Cyprus (Jalas and Suominen 1986; Greuter 1997), whereas S. aristidis and S. sessionis are two narrow Algerian endemics growing on cliffs. S. aristidis grows in tufts on protected cliffs situated about $30 \mathrm{~km}$ away from the sea. It is found in only two localities: the gorges of Lakhdaria in the Tizi Ouzou region and the gorges of Bin-Er-Redar close to Constantine (Jeanmonod 1982). S. sessionis grows on the maritime cliffs of Bejaia and seems to have disappeared from all other localities where it was collected at the beginning of the twentieth century (Jeanmonod 1985a).

The italica complex is a larger group with about 29 species, such as $S$. damboldtiana Greuter \& Melz., S. fernandezii Jeanm., S. italica (L.) Pers., S. mellifera Boiss. \& Reuter, S. mollissima (L.) Pers. and S. patula Desf. among others, which are distributed across the entire Mediterranean region. It comprises species from open rocky habitats with wide distribution ranges, such as $S$. italica, as well as chasmophytes that are mainly restricted to littoral areas, which Jeanmonod (1984) referred to as the "mollissima aggregate".

Silene nutans, one of the two species considered as independent in section Siphonomorpha (Jeanmonod 1985a, b), is a widespread polymorphic species with a large geographic range stretching from temperate Europe to Central Asia (Greuter 1995). The second species, Silene viridiflora, is found in a more restricted area (temperate Europe from Spain to Turkey) and grows as an understorey herb in forests (Fig. 1).

Both the italica complex and the paradoxa group comprise open rocky habitat species as well as chasmophytes. Chasmophytes such as $S$. aristidis, S. fruticosa and S. mollissima (endemic to the Balearic Islands) are mostly found in restricted areas, whereas open rocky habitat species either have a wider geographical range, such as $S$. italica (Northern Spain to Iran and Turkmenistan), $S$. mellifera (Iberian Peninsula), S. patula (Morocco to Tunisia) and S. paradoxa (France to Greece), or are more restricted, such as $S$. damboldtiana (endemic to northcentral Greece) and S. fernandezii (endemic to Malaga in Spain). In both groups, chasmophytes differ morphologically from species of open rocky habitats by their smaller size, woody base, contracted inflorescences, contracted basal stems and larger leaves. Jeanmonod (1985b) suggested that this pattern is due to independent evolution of both chasmophyte and open rocky habitat species within the italica complex and the paradoxa group.

Plastid and nuclear markers are frequently used in phylogeographic and population genetic studies, as they present different features. Plastid markers are haploid and generally uniparentally inherited (Birky 2008), and therefore prone to genetic drift due to smaller effective population size. As they are usually only dispersed through seeds in most angiosperms, they reflect the past colonization history of populations and species (Avise 2009). Nuclear markers are diploid and recombinant, and reflect gene flow between populations within, and sometimes between, species. Studies using both types of markers have frequently revealed incongruences between them, with chloroplast haplotypes showing geographic structure that is sometimes at odds with the accepted taxonomy, and nuclear markers more often mirroring species boundaries, as defined by morphology and ecology (Frajman and Oxelman 2007; Manen et al. 2010; Rautenberg et al. 2010; Naciri et al. 2012).

Earlier revisions of section Siphonomorpha were mainly based on morphological analyses. In this study, we used molecular markers to further investigate the genetic diversity of the paradoxa group within section Siphonomorpha sensu Jeanmonod (1985b). With that aim, we sampled herbarium specimens of the paradoxa group, the $S$. italica complex, $S$. nutans and $S$. viridiflora for DNA. 


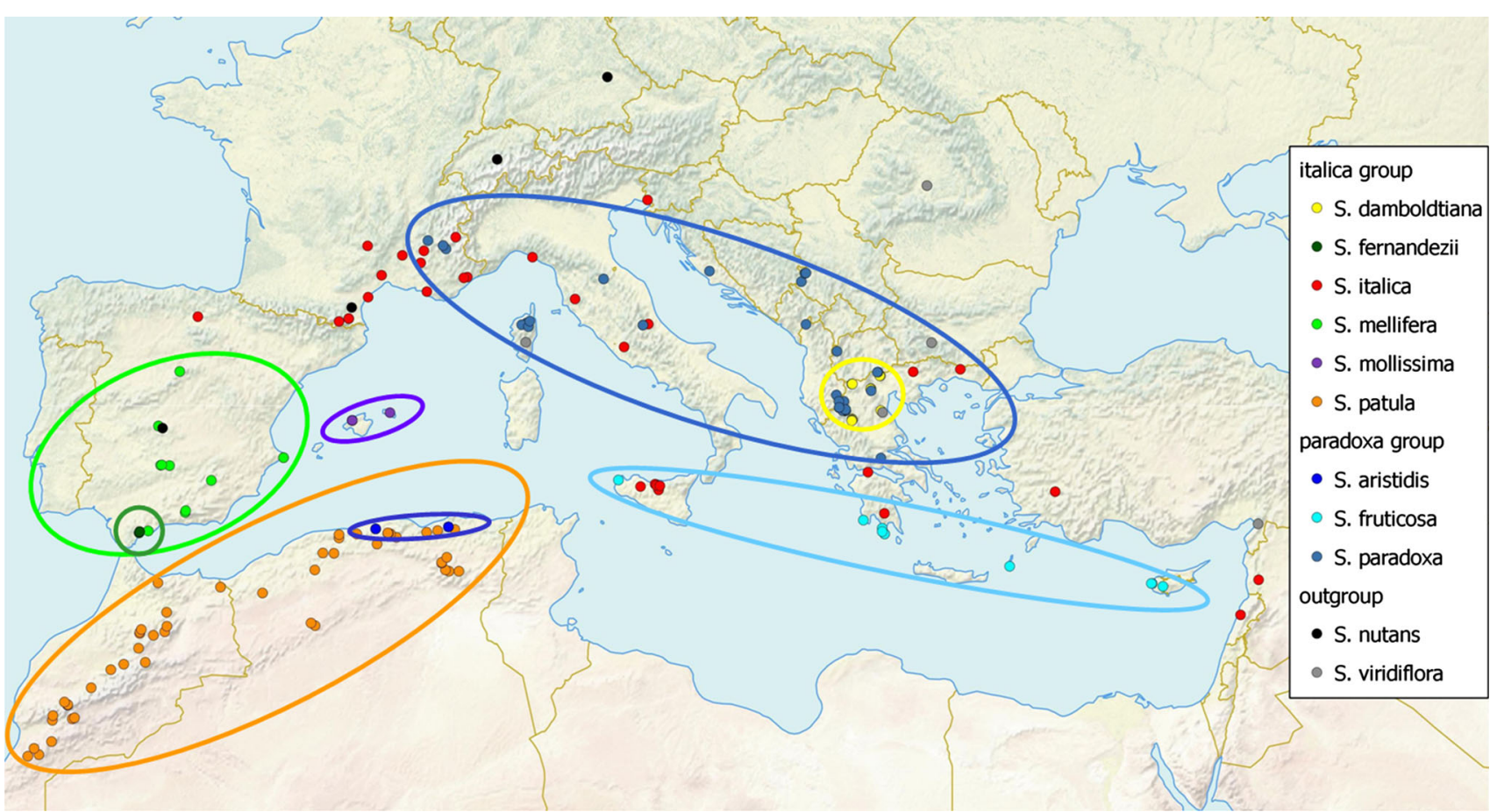

Fig. 1 Distribution of sampled individuals for the eleven species of Silene. Circles correspond to a given locality regardless of the size of the population. One individual from Iran is not shown on the map
(Suppl. Table 2). The distribution ranges of the species are indicated by coloured ellipses, except for $S$. italica, $S$. nutans and $S$. viridiflora, which are found over very large geographic ranges
We sequenced two chloroplast spacers, trn $\mathrm{H}-p s b \mathrm{~A}$ and $\operatorname{trn} \mathrm{S}-\operatorname{trn} \mathrm{G}$, as well as the nuclear ribosomal internal transcribed spacer (ITS). The chloroplast markers were chosen because they are known to display significant intraspecific variation in plant species (Ingvarsson et al. 2003; Naciri and Gaudeul 2007) and because they were already used to study the phylogeography of $S$. patula (Naciri et al. 2010). We aimed to test the validity of the paradoxa morphogroup defined by Jeanmonod (1985b) and its constituent species (S. paradoxa, S. fruticosa and S. aristidis). In particular, we wanted to answer the following questions: (1) Is the $p a$ radoxa group a genetically distinct entity within section Siphonomorpha? (2) Are the taxa of the paradoxa group distinct genetic species and, in particular, are the chasmophytes $S$. aristidis and S. fruticosa chasmophytic forms of S. paradoxa or are they well-differentiated species at the molecular level? (3) Do all the chasmophytes constitute a single lineage, at odds with the accepted taxonomy, or are they placed in different groups within section Siphonomorpha? (4) Do species of the paradoxa group show intraspecific variation (especially the only two known populations of $S$. aristidis) and are their diversity patterns related to geography?

\section{Materials and methods}

\section{Species}

Eleven Silene species of section Siphonomorpha were analysed in this study: three out of the four species of the paradoxa group (S. paradoxa, S. aristidis and S. fruticosa), no specimens being available for the Algerian endemic $S$. sessionis, six species of the italica complex ( $S$. damboldtiana, S. fernandezii, S. italica, S. mellifera, S. mollissima and $S$. patula), and the two species $S$. nutans and $S$. viridiflora. All these species are well characterized morphologically, as reported in Suppl. Table 1 (Greuter 1997; Jeanmonod 1985a, b). Species of the italica complex were chosen because they are representative of the group diversity, including both chasmophytes ( $S$. mollissima) and open rocky habitat species (S. damboldtiana, S. fernandezii, S. italica, S. mellifera and S. patula) and because they originate from across the entire distribution range of the italica complex: east (S. damboldtiana, S. italica) and west of the Mediterranean basin (S. fernandezii, S. italica, S. mellifera, S. mollissima and S. patula; Fig. 1; Suppl. Table 2). 
Sampling

Analyses were based on 120 herbarium specimens collected between 1844 and 2005 housed in the Geneva herbarium $(\mathrm{G})$ and in the ETH Zurich herbarium (ZT), as well as on fresh material of $S$. mollissima collected in 2008 and of $S$. damboldtiana collected in 2011 (Table 1 and Suppl. Table 2). We amplified and sequenced between 5 and 92 individuals for each of the species belonging to the $p a$ radoxa group and the italica complex, and also included 320 sequences of $S$. patula from a previous study (Naciri et al. 2010). S. viridiflora and S. nutans were represented by five and four individuals, respectively.

\section{DNA amplification and sequencing}

Genomic DNA was extracted from leaves of herbarium specimens and fresh material using the NucleoSpin ${ }^{\circledR}$ Plant II kit (Macherey-Nagel) or the CTAB method of Doyle and Doyle (1987). The nuclear ribosomal ITS region and the two chloroplast intergenic spacer regions trn $\mathrm{H}-p s b \mathrm{~A}$ (HA) and trnS-trnG (SG) were sequenced. ITS was amplified using the following three primers: ITS 5P, ITS 8P (Möller and Cronk 1997) and ITS1-F (Gardes and Bruns 1993), paired as ITS 5P-8P or ITS1-F-8P. The HA spacer was amplified using Hamilton's primer pair trnHpsbA (1999) or Naciri and Manen's (2010) primer pair HA3. The SG spacer was amplified using the following three primers for $t r n \mathrm{~S}$, each of them paired with $t r n \mathrm{G}$ : $t r n \mathrm{~S}$, $t r n S^{2}$, and the degenerated primer trnS-Deg (Table 2). ITS, HA and SG sequences are available in GenBank under accession numbers JX403343-JX403562, and KC466284KC466324.

Extracted DNA was amplified by polymerase chain reaction (PCR) in a total volume of $20 \mu \mathrm{l}$. The PCR mix contained $2 \mu \mathrm{l} 10 \times$ Fast Start Taq DNA Polymerase PCR Buffer $+\mathrm{MgCl}_{2}$ (Roche), $0.2 \mu \mathrm{l} 5 \%$ bovine serum albumin acetylated (BSA), $0.4 \mu \mathrm{l} 10 \mathrm{mM}$ dNTPs (Roche), $1 \mu \mathrm{l}$ of each primer $(10 \mu \mathrm{M}), 0.15 \mu \mathrm{l} 5 \mathrm{U} / \mu \mathrm{l}$ Fast Start Taq DNA Polymerase (Roche) and $1 \mu \mathrm{l}$ genomic DNA of unknown concentration. PCRs involved an initial denaturation step of $4 \mathrm{~min}$ at $95{ }^{\circ} \mathrm{C}$, followed by x cycles with $45 \mathrm{~s}$ denaturation at $95{ }^{\circ} \mathrm{C}, 1 \mathrm{~min}$ annealing at $T_{\mathrm{a}}, 1 \mathrm{~min}$ elongation at $72{ }^{\circ} \mathrm{C}$ and a final extension step of $7 \mathrm{~min}$ at $72{ }^{\circ} \mathrm{C}$ (see Table 2 for the number of cycles and the annealing temperature $T_{\mathrm{a}}$ ).

PCR products were purified using NucleoFast ${ }^{\circledR} 96$ PCR Plate (Macherey-Nagel). DNA sequencing was conducted using BigDye ${ }^{\circledR}$ Terminator v3.1 Cycle Sequencing Kit (Applied Biosystems). Both strands were sequenced separately in a $5 \mu \mathrm{l}$ reaction mix containing $0.5 \mu \mathrm{l}$ BigDye Terminator, $1 \mu \mathrm{l} 5 \times$ reaction buffer, $1 \mu \mathrm{l}$ primer $(1 \mu \mathrm{M})$, $0.5 \mu \mathrm{l}$ purified PCR product and $2 \mu \mathrm{l}$ purified water. The
Table 1 Number of specimens and number of successfully sequenced individuals for the chloroplast spacers $t r n \mathrm{H}-p s b \mathrm{~A}$ (HA), $t r n \mathrm{~S}-t r n \mathrm{G}(\mathrm{SG})$ and their combination, as well as for the nuclear ITS

\begin{tabular}{lcrrrr}
\hline Species & Individuals & HA & SG & HASG & ITS \\
\hline S. aristidis & 12 & 10 & 9 & 9 & 10 \\
S. fruticosa & 14 & 10 & 9 & 9 & 9 \\
S. paradoxa & 34 & 29 & 25 & 25 & 28 \\
S. italica & 33 & 33 & 28 & 28 & 23 \\
S. patula & 320 & 300 & 264 & 262 & 55 \\
S. mellifera & 12 & 8 & 12 & 8 & 11 \\
S. fernandezii & 5 & 4 & 5 & 4 & 5 \\
S. damboldtiana & 92 & 78 & 54 & 40 & 44 \\
S. mollissima & 13 & 13 & 13 & 13 & 13 \\
S. nutans & 4 & 4 & 4 & 4 & 4 \\
S. viridiflora & 5 & 4 & 4 & 4 & 5 \\
Total & 544 & 493 & 427 & 406 & 207 \\
\hline
\end{tabular}

Sequences of $S$. patula were published in Naciri et al. (2010)

Table 2 Primers used in PCR and sequencing reactions including annealing temperature $\left(T_{\mathrm{a}}\right)$ and number of cycles (cycle $\mathrm{nb}$ )

\begin{tabular}{|c|c|c|c|c|}
\hline Primer & $5^{\prime}-3^{\prime}$ sequence & References & $\begin{array}{l}T_{\mathrm{a}} \\
{\left[{ }^{\circ} \mathrm{C}\right]}\end{array}$ & $\begin{array}{l}\text { Cycle } \\
\mathrm{nb}\end{array}$ \\
\hline $\begin{array}{l}\text { ITS } \\
5 \mathrm{P}\end{array}$ & $\begin{array}{l}\text { GGA AGG AGA AGT } \\
\text { CGT AAC AAG G }\end{array}$ & $\begin{array}{l}\text { Möller and } \\
\text { Cronk } \\
\text { (1997) }\end{array}$ & 59 & 45 \\
\hline $\begin{array}{l}\text { ITS } \\
8 \mathrm{P}\end{array}$ & $\begin{array}{l}\text { CAC GCT TCT CCA GAC } \\
\text { TAC A }\end{array}$ & $\begin{array}{l}\text { Möller and } \\
\text { Cronk } \\
\text { (1997) }\end{array}$ & 59 & 45 \\
\hline $\begin{array}{l}\text { ITS1- } \\
\text { F }\end{array}$ & $\begin{array}{l}\text { CTT GGT CAT TTA GAG } \\
\text { GAA GTA A }\end{array}$ & $\begin{array}{l}\text { Gardes and } \\
\text { Bruns } \\
(1993)\end{array}$ & 59 & 45 \\
\hline $\operatorname{trn} \mathrm{H}$ & $\begin{array}{l}\text { ACT GCC TTG ATC CAC } \\
\text { TTG GC }\end{array}$ & $\begin{array}{l}\text { Hamilton } \\
\text { (1999) }\end{array}$ & 52 & 35 \\
\hline$p s b \mathrm{~A}$ & $\begin{array}{l}\text { CGA AGC TCC ATC TAC } \\
\text { AAA TGG }\end{array}$ & $\begin{array}{l}\text { Hamilton } \\
\text { (1999) }\end{array}$ & 52 & 35 \\
\hline $\operatorname{trn} \mathrm{H}^{3}$ & $\begin{array}{l}\text { AAC CCG CGC ATG } \\
\text { GTG GAT TC }\end{array}$ & $\begin{array}{l}\text { Naciri and } \\
\text { Manen } \\
(2010)\end{array}$ & 52 & 40 \\
\hline$p s b \mathrm{~A}^{3}$ & $\begin{array}{l}\text { CCT CTA GAC CTA GCT } \\
\text { GCT AT }\end{array}$ & $\begin{array}{l}\text { Naciri and } \\
\text { Manen } \\
(2010)\end{array}$ & 52 & 40 \\
\hline $\operatorname{trnS}$ & $\begin{array}{l}\text { GCC GCT TTA GTC CAC } \\
\text { TCA GC }\end{array}$ & $\begin{array}{l}\text { Hamilton } \\
\text { (1999) }\end{array}$ & 52 & 45 \\
\hline $\operatorname{trn} \mathrm{G}$ & $\begin{array}{c}\text { GAA CGA ATC ACA } \\
\text { CTT TTA CCA C }\end{array}$ & $\begin{array}{l}\text { Hamilton } \\
\text { (1999) }\end{array}$ & 52 & 45 \\
\hline $\operatorname{trn} \mathrm{S}^{2}$ & $\begin{array}{l}\text { TCG TAC AAC GGA TTA } \\
\text { GCA ATC C }\end{array}$ & $\begin{array}{l}\text { Designed by } \\
\text { the authors }\end{array}$ & 52 & 45 \\
\hline $\begin{array}{l}\text { trnS- } \\
\text { Deg }\end{array}$ & $\begin{array}{c}\text { G(CA)C GCT TT(AC) } \\
\text { GTC CAC TCA GC }\end{array}$ & $\begin{array}{l}\text { Designed by } \\
\text { the authors }\end{array}$ & 52 & 45 \\
\hline
\end{tabular}

sequence reactions consisted of 25 cycles of $10 \mathrm{~s}$ denaturation at $96{ }^{\circ} \mathrm{C}, 5 \mathrm{~s}$ annealing at $50{ }^{\circ} \mathrm{C}$ and 4 min elongation at $60{ }^{\circ} \mathrm{C}$. An ABI PRISM ${ }^{\mathrm{TM}} 377$ DNA Sequencer (Applied Biosystems) was used to run sequence reactions. 
Individuals of $S$. patula and S. italica showing two or more ambiguous sites in ITS were cloned in Escherichia coli to allow a clear determination of the mutational phase. The ligation mix contained $5 \mu \mathrm{l} 2 \times$ ligation buffer (Promega), $1 \mu \mathrm{l}$ pGEM-T vector, $1 \mu \mathrm{l}$ T4 DNA ligase, $2 \mu \mathrm{l}$ PCR product and $1 \mu \mathrm{l}$ ultra-pure water. Molecular cloning was carried out using the pGEM-T vector system A3610 with JM109 High Efficiency Competent Cells (Promega) following the manufacturer's protocols. At least five clones were sequenced per PCR product (maximum ten clones).

\section{Sequence analyses}

The sequences were assembled using the Sequencher ${ }^{\mathrm{TM}} 4.8$ DNA Sequencing software (Gene Codes Corporation, Ann Arbor, Michigan, USA) and were aligned using the BioEdit Sequence Editor 7.0.9 (Hall 1999). Gaps (indels) were positioned as described by Naciri et al. (2010) to minimize the number of step mutations among sequences. Indels that were previously shown to carry high information content at the intraspecific level in Silene (Ingvarsson et al. 2003; Naciri et al. 2010) were coded using Barriel's strategy (1994).

The data were analysed using a population geneticbased approach as recommended by Posada and Crandall (2001) when analysing intraspecific gene genealogies. Median-joining networks were drawn using Network 4.6.1.0 (Bandelt et al. 1999). For each locus, a separate network was calculated. Subsequently, the haplotypes for the two chloroplast loci HA and SG were concatenated for each individual and used to calculate a unique network. The software network relies on mutation tables without the possibility to use question marks in mutation coding. To deal with the unknown state of mutations in indel zones for individuals with a deletion, we assumed that the deleted base was one of the bases seen in the other individuals. For network building, all mutations, i.e., indels or substitutions, were weighted equally in a first run. In a second and final run, the mutations were weighted inversely proportional to the number of times they appeared in the network in order to weight down putative homoplasic sites (Bandelt et al. 1999).

ITS is a multicopy gene family undergoing concerted evolution, recombination and reorganization. Intra-individual polymorphism is therefore frequently observed (Àlvarez and Wendel 2003; Grimm and Denk 2010). However, for $65 \%$ of all individuals we analysed, zero to one ambiguity was observed, and the characterization of ITS variants was easily deduced. Mutational phases for individuals of $S$. patula and $S$. italica with more than two ambiguous states were inferred from 5 to 10 clones per individual. In all cases, the ITS variant phase was also deduced using the software Phase version 2.1.1 that reconstructs haplotypes from population data using a Bayesian approach (Stephens et al. 2001). Phase was run using the default option on each species separately. The term ITS variant was used in all cases, since it was not possible to assess whether the variants were homologous (representing the same gene) or homeologous [representing paralogues resulting from gene duplication; Grimm and Denk (2010)]. Subsequently, a ITS variant-based network was computed following the same procedure as for the chloroplast markers.

Gene diversity $h$ (Nei 1987) and nucleotide diversity $\pi$ (Tajima 1983, 1993), as well as their standard deviations, were computed using the Arlequin software version 3.5 (Excoffier and Lischer 2010) for the chloroplast and nuclear markers. These indices are corrected for sample size and can therefore be compared across samples. Due to very small sample sizes, $S$. nutans and $S$. viridiflora were excluded from these analyses. Tests for sequence selective neutrality were computed using Tajima's $D$ and Fu's $F$ s statistics (Fu 1997; Tajima 1983) in Arlequin for the chloroplast markers. The proportion of heterogeneous genotypes (i.e. genotypes showing sequence ambiguities) was computed for ITS. A Fisher's exact test was used to compare proportions of heterogeneous genotypes.

For the concatenated chloroplast markers, mismatch distributions were carried out within species, and the observed pattern was compared to those obtained under two different demographic scenarios in Arlequin: a sudden demographic expansion for which the species flushed from $N_{0}$ to $N_{1}$ (with $N_{1} \gg N_{0}$ ) sometime in the past, or a spatial expansion in which the species expanded in space by means of the creation of new populations of the same size and the exchange of migrants with other populations. Goodness-of-fit was used as statistical test to accept or reject a given scenario and was calculated from the sum of the squared differences between the observed and the simulated data (SSD), (Excoffier et al. 2005).

\section{Results}

Chloroplast alignments and haplotypes

The HA sequences were highly similar at both ends and could be aligned without difficulty. The only exception was a $76 \mathrm{bp}$ stretch in the middle of the sequence of $S$. nutans and $S$. viridiflora, which was treated as a large insertion in these species. Conversely, a $91 \mathrm{bp}$ fragment that was present in all other sequences was treated as a large deletion in S. nutans and S. viridiflora. Sequences of S. nutans and $S$. viridiflora were much more similar to all other sequences for SG than for HA. The full alignments for all 

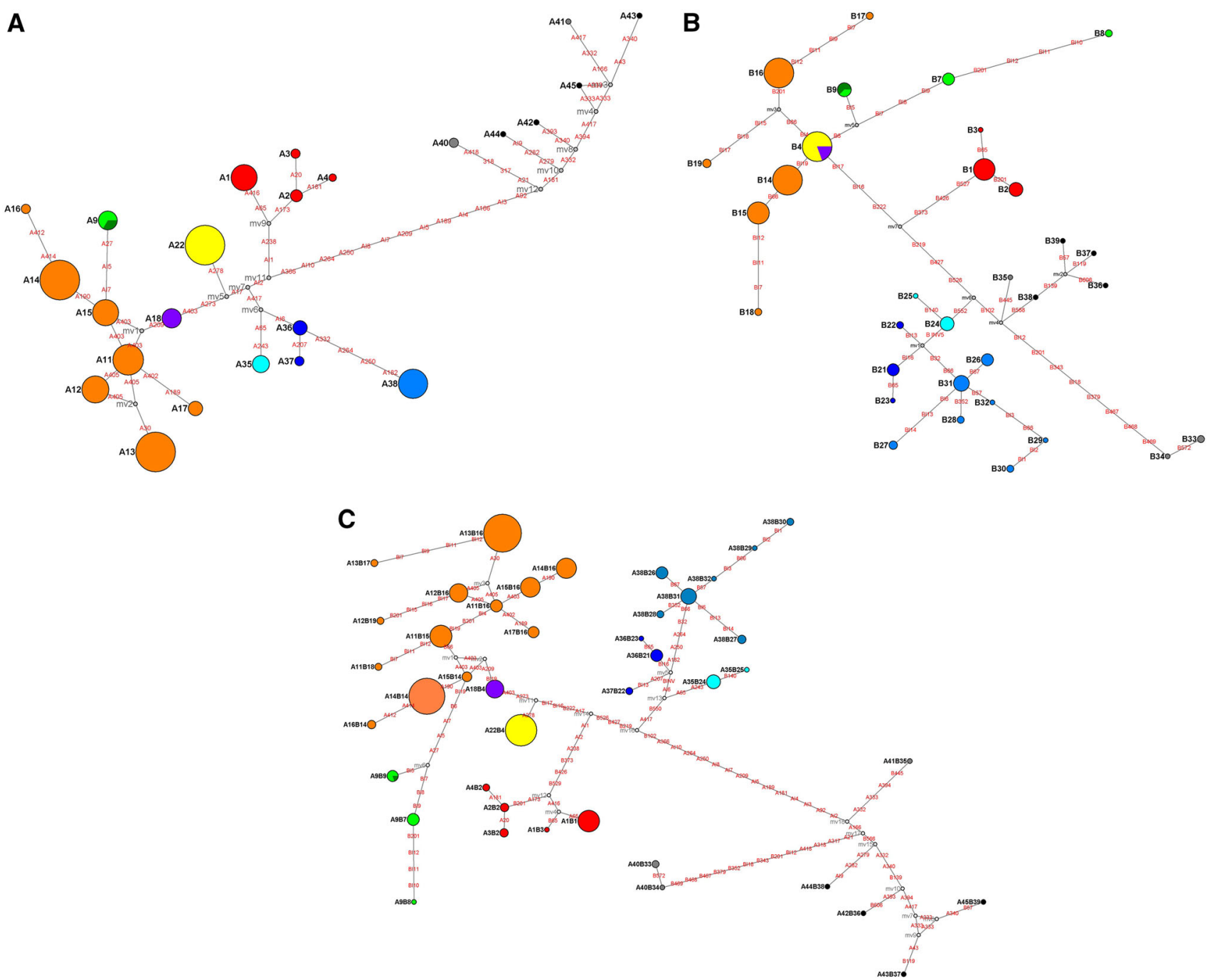

Fig. 2 Haplotype network for the chloroplast intergenic spacers $\operatorname{trn} \mathrm{H}-p \operatorname{sbA}(\mathbf{a}), \operatorname{trnS}-\operatorname{trn} \mathrm{G}$ (b) and the two concatenate loci (c). Haplotype names are in black, intermediate nodes in light grey and mutations in red. Species are coloured as in Fig. 1 (S. paradoxa in

the species had a length of 425 and 632 bp for HA and SG, respectively.

Silene paradoxa, S. fruticosa, S. mollissima and $S$. damboldtiana did not show any intraspecific variation for HA and presented haplotypes A38, A35, A18 and A22, respectively (Fig. 2a and Suppl. Table 3). Silene mellifera and $S$. fernandezii shared a unique haplotype A9. The other studied species showed intraspecific variability, with haplotypes number ranging from two (A36 and A37 for S. aristidis; $\mathrm{A} 40$ and $\mathrm{A} 41$ for $S$. viridiflora) to four (A1-A4 for S. italica; A42-A45 for $S$. nutans). The seven haplotypes for S. patula (A11-A17) were obtained from Naciri et al. (2010), but are added to Suppl. Table 3 to account for new mutations in the other species.

Five of the eleven species studied showed more intraspecific variation for SG than for HA. Seven haplotypes blue, S. fruticosa in turquoise, S. aristidis in dark blue, S. patula in orange, $S$. italica in red, $S$. damboldtiana in yellow, $S$. fernandezii in dark green, $S$. mellifera in light green, $S$. mollissima in violet, $S$. nutans in black and S. viridiflora in grey)

(B26-B32) were found for S. paradoxa, two (B24 and B25) for S. fruticosa, three (B21-B23) for S. aristidis, three (B33-B35) for S. viridiflora and three for S. mellifera (B7B9; Fig. 2b and Suppl. Table 4). For S. italica, only three haplotypes (B1-B3) were found, whereas for $S$. damboldtiana (B4), S. mollissima (B4), S. fernandezii (B9) and S. nutans (B36-B39), the haplotype number did not change compared to HA. All individuals of $S$. damboldtiana had the haplotype B4 that was shared with $S$. mollissima. Some individuals of $S$. mellifera had the same haplotype as $S$. fernandezii.

In total, 144 individuals were fully sequenced for both chloroplast loci, yielding 30 different haplotypes for the ten species when combining the haplotypes of HA and SG, which becomes 11 species, 406 individuals and 43 concatenated haplotypes if $S$. patula is included (Table 1). All haplotypes, 
except A9B9, which is shared between $S$. mellifera and $S$. fernandezii, were species-specific. For all polymorphic species, Tajima's and Fu's tests were non-significant, implying selective neutrality of the chloroplast markers.

\section{Chloroplast networks}

A total of 406 individuals of the eleven studied species were used for chloroplast network analyses. Haplotype networks were calculated separately for HA and SG before the two data sets were concatenated (Fig. 2).

In the separate network for HA, all haplotypes were grouped according to the species they belong to, except for S. mellifera and S. fernandezii, which share haplotype A9, and for S. nutans and S. viridiflora, which were grouped together (Fig. 2a). Silene nutans and S. viridiflora were separated by at least 20 mutations from all other species. Species were also clustered in the SG network (Fig. 2b), except two pairs of species that share the same haplotypes, namely S. damboldtiana and S. mollissima (B4) and $S$. mellifera and S. fernandezii (B9), respectively. Silene damboldtiana was more closely related to $S$. patula based on the SG sequences than for the HA sequences, while $S$. nutans and one S. viridiflora individual (haplotype B35) were only separated by three mutations from $S$. fruticosa and the paradoxa group.

The concatenated haplotype network of the chloroplast loci HA and SG showed that sequences from seven of the nine densely sampled species clustered according to their species affiliation and form separate entities from the other species (Fig. 2c). Silene fernandezii and S. mellifera were exceptions because they share the same haplotype A9B9. $S$. paradoxa, S. fruticosa and S. aristidis were clustered together and situated in the middle of the network between S. italica and S. viridiflora-S. nutans (Fig. 2c). S. paradoxa haplotype A38B31 from Greece and Serbia was situated at the base of all other haplotypes recorded for the species, whereas the most distal haplotype was found in Italy (A38B30). For $S$. fruticosa, the most common haplotype (A35B24) was found in southern Greece, Karpathos and Cyprus, whereas haplotype A35B25, located at one tip of the network, was found in Italy (Sicily). Silene aristidis had three haplotypes, of which A37B22 was recorded in individuals from Constantine, whereas A36B21 and A36B23 were found in individuals from Tizi-Ouzou (both Algerian localities). Haplotypes of $S$. italica were divided into two lineages, A1B1 and A1B3 from France and Italy and $\mathrm{A} 2 \mathrm{~B} 2, \mathrm{~A} 3 \mathrm{~B} 2$ and $\mathrm{A} 4 \mathrm{~B} 2$ from Greece, Turkey, Iran and north-eastern Italy. The west-Mediterranean species $S$. patula, S. mellifera and S. fernandezii were located at one end of the network, whereas $S$. viridiflora and $S$. nutans, which grow in temperate Europe and Central Asia, were located at the other end (Fig. 2c).
Chloroplast diversity and demographic scenarios

Gene diversity $(h)$ and nucleotide diversity $(\pi)$ were computed for chloroplast markers for the nine densely sampled species (Table 3 ). Gene diversity was high for $S$. paradoxa and $S$. patula, intermediate for $S$. aristidis, $S$. italica and $S$. mellifera, low for $S$. fruticosa and non-existent for $S$. damboldtiana, S. fernandezii and S. mollissima, which all had only one haplotype. Nucleotide diversity did not exceed $4.15 \times 10^{-3} \pm 2.36 \times 10^{-3}$ ( $S$. patula), being as low as $0.31 \times 10^{-3} \pm 0.45 \times 10^{-3}$ for S. fruticosa (Table 3).

$P$ values for demographic and spatial expansion scenarios were computed for the six species showing withinspecies diversity for the chloroplast markers (Table 4). A spatial expansion scenario could not be rejected for any species, whereas a demographic expansion scenario was strongly rejected for S. aristidis, S. italica and S. mellifera, with $P$ values lower than 0.001 . For $S$. paradoxa, however, a demographic expansion model showed stronger statistical support than a spatial expansion model, whereas the opposite was true for S. fruticosa and S. patula.

\section{Nuclear diversity}

The ITS sequences were aligned to a consensus length of $711 \mathrm{bp}$, which included the whole ITS1, the 5.8S ribosomal RNA, ITS2, 82 bp of the $26 \mathrm{~S}$ ribosomal RNA and no indels. A total of 207 individuals were successfully amplified for ITS, yielding 94 ITS variants when including $S$. patula (Table 5, Suppl. Table 5). ITS variant reconstruction using phase always matched the cloned sequences when available. In all ambiguous situations, phase defined one best combination of ITS variants. The ITS network (Fig. 3) showed a clear clustering of three entities that grouped together the species of the paradoxa group, of the italica complex and of $S$. nutans and $S$. viridiflora, respectively. Con-specific sequences of $S$. paradoxa, $S$. fruticosa and $S$. aristidis were grouped according to species affiliation, with the $S$. paradoxa ITS variant I45 being found at the base of the paradoxa group. This ITS variant was seen in S. paradoxa individuals across the entire sampling region, namely France, Italy, the former Yugoslavia and Greece. All other S. paradoxa ITS variants were found in specimens from France or Italy (I49, I50, I51, I52, I53 and I54) excepting I46 that was seen in a single individual of Serbia, as well as I47 and I48 that were recorded in two individuals from Greece. A highly significant trend towards more homogeneous ITS genotypes was observed in Greece and the Balkans when compared to Italy and France (83 and $20 \%$, respectively, $P_{\text {Fisher Exact Test }}=0.002$ ). All the $S$. fruticosa ITS variants were linked to I45 and were divided into two lineages found either in Italy (I43 and I44) or in Greece, Karpathos Island and Cyprus (I40-I42). Silene aristidis was divided into two 
Table 3 Gene diversity $(h)$ and nucleotide diversity $(\pi)$ for $S$. paradoxa, $S$. aristidis, $S$. fruticosa, S. italica, $S$. damboltiana and S. patula for the $t r n \mathrm{H}-p s b \mathrm{~A}$ and $t r n \mathrm{~S}-\operatorname{trn} \mathrm{G}$ combined chloroplast haplotypes

\begin{tabular}{|c|c|c|c|c|}
\hline Species & $\begin{array}{l}\mathrm{Nb} \text { of } \\
\text { individuals }\end{array}$ & Haplotypes ( $\mathrm{Nb}$ of individuals) & $\begin{array}{l}\text { Gene diversity } \\
h \pm \mathrm{SD}\end{array}$ & $\begin{array}{l}\text { Nucleotide } \\
\text { diversity } \\
\pi \pm \mathrm{SD}^{\mathrm{a}}\end{array}$ \\
\hline S. aristidis & 9 & $\begin{array}{l}\mathrm{A} 36 \mathrm{~B} 21(6), \mathrm{A} 36 \mathrm{~B} 23(1), \mathrm{A} 37 \mathrm{~B} 22 \\
(2)\end{array}$ & $0.5556 \pm 0.1653$ & $1.892 \pm 1.450$ \\
\hline S. fruticosa & 9 & A35B24 (8), A35B25 (1) & $0.2222 \pm 0.1662$ & $0.305 \pm 0.449$ \\
\hline S. paradoxa & 25 & $\begin{array}{l}\text { A38B26 (6), A38B27 (3), A38B28 } \\
\text { (2), A38B29 (1), A38B30 (2), } \\
\text { A38B31 (10), A38B32 (1) }\end{array}$ & $0.7833 \pm 0.0597$ & $3.100 \pm 1.958$ \\
\hline S. italica & 28 & $\begin{array}{l}\text { A1B1 (19), A1B2 (1), A2B2 (3), } \\
\text { A3B2 (3), A4B2 (2) }\end{array}$ & $0.5291 \pm 0.1051$ & $1.820 \pm 1.319$ \\
\hline S. patula & 262 & $\begin{array}{l}\text { A11B15 (20), A11B16 (6), A11B18 } \\
\text { (2), A12B16 (14), A12B19 (2), } \\
\text { A13B16 (118), A13B17 (2), } \\
\text { A14B14 (4), A14B16 (17), A15B14 } \\
\text { (4), A15B16 (16), A16B14 (3), } \\
\text { A17B16 (5) }\end{array}$ & $0.7410 \pm 0.0223$ & $4.152 \pm 2.358$ \\
\hline S. mellifera & 8 & A9B7(6), A9B8(1), A9B9(1) & $0.4643 \pm 0.2000$ & $2.321 \pm 1.710$ \\
\hline S. fernandezii & 4 & A9B9(4) & $0.0000 \pm 0.0000$ & $0.000 \pm 0.000$ \\
\hline S. damboldtiana & 40 & A22B4 (40) & $0.0000 \pm 0.0000$ & $0.000 \pm 0.000$ \\
\hline S. mollissima & 13 & $\mathrm{~A} 18 \mathrm{~B} 4(13)$ & $0.0000 \pm 0.0000$ & $0.000 \pm 0.000$ \\
\hline
\end{tabular}

a Numbers were multiplied by a factor of 1,000
Gene and nucleotide diversities as well as the percentage of heterogeneous genotypes were computed for all the densely sampled species. Gene diversity was high for the six species of the italica complex (about 0.9) except for S. fernandezii and S. mollissima, whereas it was lower and more variable for the paradoxa group, ranging from $0.44 \pm 0.08$ to $0.76 \pm 0.06$ (Table 5). The nucleotide diversity $\pi$ was low for $S$. paradoxa $\left(1.3 \times 10^{-3} \pm 1.0 \times 10^{-3}\right)$ and $S$. fruticosa $\left(1.4 \times 10^{-3} \pm 1.1 \times 10^{-3}\right)$ and about twice as high for the other species, except $S$. fernandezii and S. mollissima, again. The proportion of heterogeneous genotypes ranged between 30 and $39 \%$ for the paradoxa group and between 40 and $85 \%$ for the italica complex with the noticeable exception of S. mollissima, for which most of the individuals were homogenous for ITS.

\section{Discussion}

The paradoxa group is genetically circumscribed within the section

The sequence data of one nuclear and two chloroplast loci show that species of the paradoxa group cluster together within section Siphonomorpha sensu Jeanmonod (Figs. 2, 3). According to nuclear data, section Siphonomorpha is clustered into a minimum of three distinct groups: $p a$ radoxa, italica and nutans-viridiflora, in agreement with Jeanmonod's (1985b) taxonomic classification based on morphological data. This gives support to the existence of a cohesive paradoxa group separated from the italica 
Table 5 Alleles, gene diversity $h$ and nucleotide diversity $\pi$ with their respective standard deviation, as well as the proportion of heterogeneous genotypes for the nuclear marker ITS for all the studied species except $S$. nutans and $S$. viridiflora

\begin{tabular}{|c|c|c|c|c|c|}
\hline Species & $\begin{array}{l}\mathrm{Nb} \text { of } \\
\text { individuals }\end{array}$ & Alleles (nb) & $\begin{array}{l}\text { Gene diversity } \\
h \pm \mathrm{SD}\end{array}$ & $\begin{array}{l}\text { Nucleotide } \\
\text { diversity } \\
\pi \pm \mathrm{SD}^{\mathrm{a}}\end{array}$ & $\begin{array}{l}\text { Heterogenous } \\
\text { genotypes (\%) }\end{array}$ \\
\hline S. aristidis & 10 & $\begin{array}{l}\text { I34 (8), I36 (5), } \\
\text { I37 (4), I38 (2), } \\
\text { I39 (1) }\end{array}$ & $0.7632 \pm 0.0595$ & $2.620 \pm 1.748$ & 30.00 \\
\hline S. fruticosa & 9 & $\begin{array}{l}\text { I40 (12), I41 (3), } \\
\text { I42 (1), I43 (1), } \\
\text { I44 (1) }\end{array}$ & $0.5490 \pm 0.1272$ & $1.418 \pm 1.117$ & 33.33 \\
\hline S. paradoxa & 28 & $\begin{array}{c}\text { I45 (42), I46 (1), } \\
\text { I47 (1), I48 (1), } \\
\text { I49 (2), I50 (3), } \\
\text { I51 (1), I52 (3), } \\
\text { I53 (1), I54 (1) }\end{array}$ & $0.4351 \pm 0.0823$ & $1.330 \pm 1.027$ & 39.29 \\
\hline S. italica & 23 & $\begin{array}{l}\text { I13 (2), I56 (4), } \\
\text { I58 (1), I59 (1), } \\
\text { I60 (11), I61 (9), } \\
\text { I62 (6), I63 (1), } \\
\text { I64 (1), I67 (1), } \\
\text { I68 (3), I69 (2), } \\
\text { I70 (1), I71 (1), } \\
\text { I79 (2) }\end{array}$ & $0.8937 \pm 0.0247$ & $3.210 \pm 1.992$ & 78.26 \\
\hline S. patula & 55 & $\begin{array}{l}\text { I1 (4), I2 (17), I3 } \\
(28), \text { I4 (17), I5 } \\
\text { (2), I7 (4), I8 (2), } \\
\text { I9 (3), I10 (5), } \\
\text { I11 (1), I12 (1), } \\
\text { I13 (2), I14 (1), } \\
\text { I16 (1), I17 (2), } \\
\text { I18 (1), I19 (2), } \\
\text { I20 (1), I21 (1), } \\
\text { I22 (6), I24 (1), } \\
\text { I25 (1), I26 (1), } \\
\text { I27 (1), I29 (2), } \\
\text { I31 (2), I55 (1) }\end{array}$ & $0.8981 \pm 0.0173$ & $3.260 \pm 2.166$ & 80.00 \\
\hline S. mellifera & 11 & $\begin{array}{l}\text { I98 (6), I99 (2), } \\
\text { I100 (6), I103 } \\
(1), \text { I104 (1), } \\
\text { I105 (2), I106 (4) }\end{array}$ & $0.8355 \pm 0.00443$ & $3.343 \pm 2.110$ & 45.45 \\
\hline S. fernandezii & 5 & I4 (2) I99 (8) & $0.3553 \pm 0.1591$ & $0.500 \pm 0.597$ & 40.00 \\
\hline S. damboldtiana & 44 & $\begin{array}{l}\text { I4 }(22), \text { I13 (1), } \\
\text { I30 (1), I33 (1), } \\
\text { I61 (21), I66 (1), } \\
\text { I84 (5), I85 (5), } \\
\text { I87 (11), I90 (1), } \\
\text { I91 (2), I92 (7), } \\
\text { I93 (4), I95 (3), } \\
\text { I96 (1), I97 (2) }\end{array}$ & $0.8568 \pm 0.0207$ & $2.957 \pm 1.846$ & 85.08 \\
\hline S. mollissima & 13 & I101 (25) I102 (1) & $0.0769 \pm 0.0697$ & $0.108 \pm 0.240$ & 7.69 \\
\hline
\end{tabular}

a Numbers were multiplied by a factor of 1,000 paradoxa and $S$. italica, respectively), with $S$. viridiflora and $S$. nutans being also found in the three latter countries (Fig. 1).

Both the chloroplast haplotypes and the ITS variants were species-specific in the paradoxa group. In contrast, several species of the italica complex shared haplotypes (S. fernandezii and S. mellifera) or ITS variants, such as S. italica, S. damboldtiana, S. patula, S. fernandezii and 


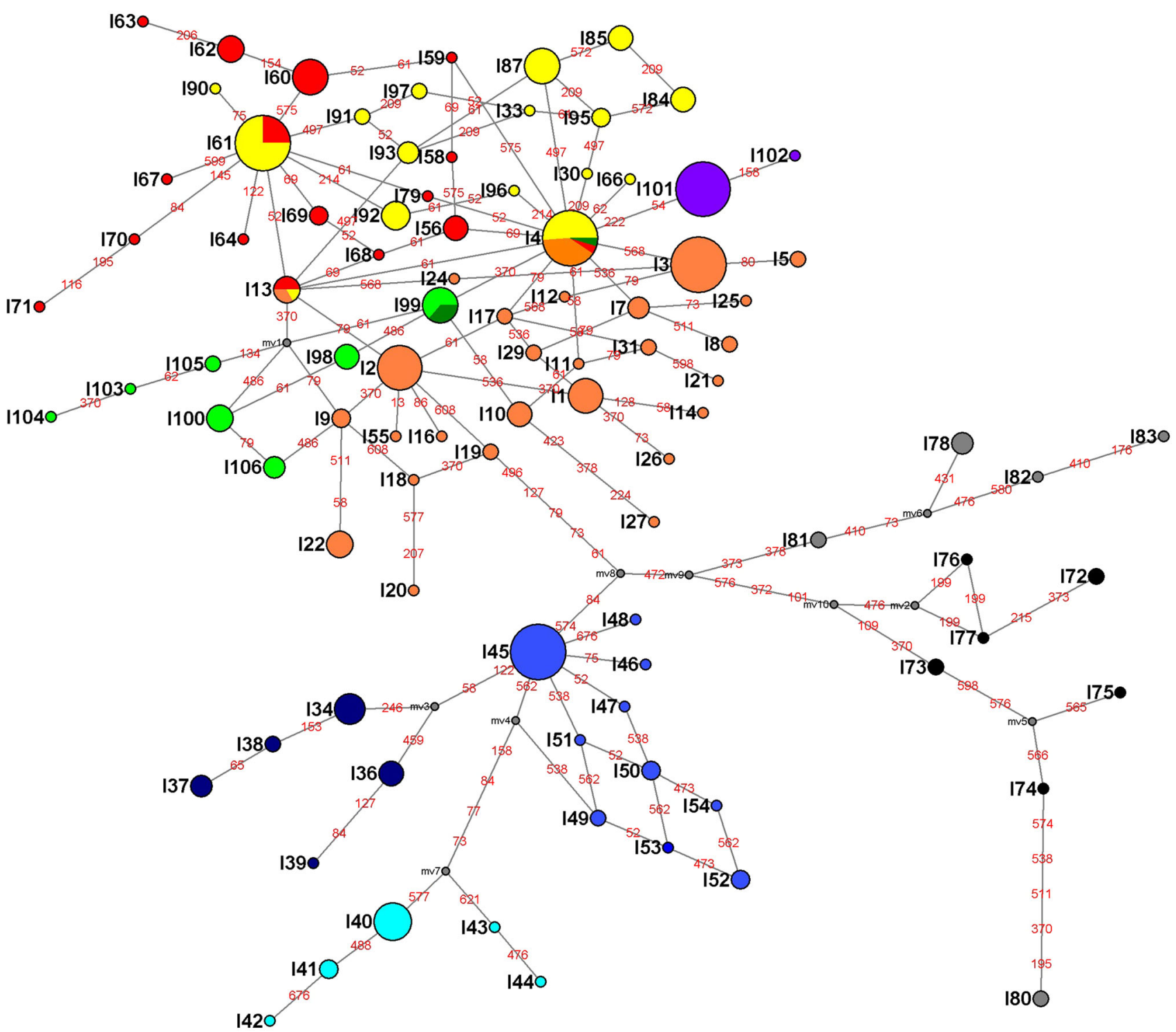

Fig. 3 Median-joining network for ITS. Note the shared ITS variants in the italica group. ITS variant names (corresponding to Table 3 and to Supplementary Table 5) are in black, intermediate nodes in light

S. mellifera (Figs. 2 and 3). Similar chloroplast sharing was found among Silene species in section Melandrium by Rautenberg et al. (2010) and explained as footprints of extensive hybridization and backcrossing events. Naciri et al. (2012) showed that nuclear markers (and ITS in particular) are generally more accurate in delineating species than chloroplast markers, the latter more often reflecting hybridization and chloroplast capture events. This was the case in the paradoxa group (and in section Melandrium) but not in the italica complex for which incomplete lineage sorting is seen for ITS. This pattern probably points to more recent speciation events in the italica complex than in the paradoxa group or to recent and/or ongoing hybridization in the former complex. grey and mutation positions in red. Species colour codes are given as in Figs. 1, 2

The split of $S$. nutans and S. viridiflora from all other species is more marked for the chloroplast than for the ITS data. This is due to the large indel in HA and subsequent mutations, as well as to at least seven additional mutations in HA and one in SG that distinguish S. nutans and S. viridiflora from all other species. More samples are, however, needed for these two species to have a clear idea of their intraspecific diversity and their respective delimitation.

Chasmophyte species belong to different evolutionary lineages

Results from the analysis of the paradoxa group and the italica complex allow us to reject the hypothesis according 
to which chasmophytes and species from open rocky habitats belong to two different evolutionary lineages. Chasmophytes are found in both the italica complex and paradoxa group. Since most species within section $\mathrm{Si}$ phonomorpha and in other closely related sections are open rocky habitat species, and given the restricted geographic occurrence of chasmophyte species, it is likely that chasmophyte forms evolved from open rocky habitat species, as suggested by Jeanmonod and Mascherpa (1982), and not the other way round. According to this hypothesis, chasmophyte forms would have appeared as local ecotypes of more widely distributed species that became isolated enough to behave as separate species. More evidence and a character reconstruction analysis are, however, needed to fully assess the direction of the switch.

The paradoxa group is constituted by three distinct species

In agreement with morphological and ecological data, our results strongly suggest that $S$. fruticosa and $S$. aristidis are distinct taxa from S. paradoxa. Jeanmonod (1985a) stated that the chasmophytes $S$. fruticosa and $S$. aristidis originated from $S$. paradoxa that grows in open rocky habitats and that the latter species is more ancestral. Our results are not fully conclusive on this issue. According to coalescence criteria, the oldest ancestral haplotype is the most frequent one, or the one with the highest number of connections within the network, and therefore often the most central haplotype (Posada and Crandall 2001). In our case, the chloroplast network clearly indicates that A38B31 is the most ancestral haplotype for S. paradoxa, but no existing haplotype can be assigned as most ancestral for the whole group. Indeed, the best candidates for the most ancestral haplotype were either not sampled or are extinct (mv13 or mv16), which is also the case for many other intermediate haplotypes. This can be due to a high genetic drift for chloroplast markers, which possibly led to the extinction of other haplotypes that might have belonged to S. paradoxa or to an ancestral, less specialized and more widely distributed species before speciation and adaptation took place. The latter statement can receive some support from the nuclear network in which the most central, the most connected and the most frequent ITS variant is found in $S$. paradoxa (I45).

All species of the paradoxa group show intraspecific variation and geographic structure

Chloroplast sequences for $S$. paradoxa were very variable with gene and nucleotide diversities comparable to those of S. patula, a better sampled species (Table 3; Naciri et al.
2010). This was not the case for the nuclear marker, for which $S$. paradoxa displayed only half the gene and nucleotide diversities of $S$. patula (Table 5). The low proportion of heterogeneous ITS genotypes might indicate an ancient differentiation of the species followed by efficient concerted evolution and gene conversion when compared to species of the italica complex. None of the two expansion models could be rejected for S. paradoxa, but a demographic expansion scenario fits the data better than a spatial expansion scenario according to $P$ values. This is supported by the chloroplast network, which shows a star-like arrangement of $S$. paradoxa haplotypes as well as a negative, although non-significant, Tajima's $D$ index, indicating an excess of unique haplotypes, a sign of a demographic expansion (Tajima 1993). According to the geographic distribution of haplotype A38B31, which can be considered as the most ancestral in the species because of its central position (Posada and Crandall 2001), the centre of origin or possibly the origin of the demographic expansion might be located in Greece or the former Yugoslavia, with subsequent expansion and haplotype diversification north- and westwards towards Italy and France. The fact that a higher proportion of homogeneous genotypes were found in Greece and the Balkans, when compared to France and Italy, may be the sign of a more recent colonization of the latter regions. Interestingly, the most important serpentinite areas in Europe are in the Balkan Peninsula followed by the Italian Peninsula (Roberts and Proctor 1992). All our results are congruent with an adaptation of the species in the Balkans followed by a migration and a diversification towards the Italian Peninsula and France. In the absence of any molecular clock or known mutation rate for the chloroplast markers, it is difficult to assess when this demographic expansion occurred. The distribution area of the species is mostly continental, excepting Corsica. The colonization of this island could have taken place during the Messinian Salinity Crisis, when Corsica was connected to the Continent or, afterwards, through a long-distance dispersal mediated by birds.

Silene fruticosa displayed only two haplotypes and five ITS variants, which is surprising for a species with such a large and fragmented distribution range. The species displays haplotype A35B25 in Sicily and haplotype A35B24 in southern Greece, Karpathos and Cyprus that are separated from each other by the sea. In contrast to $S$. paradoxa, a spatial expansion scenario fitted the data better than a demographic expansion scenario. This may be the explanation for the reduced number of haplotypes because spatial expansion can lead to haplotype surfing on the edge of the expansion wave and then to large geographical ranges with a unique haplotype, as observed here (Klopfstein et al. 2006). If an expansion occurred, it should mainly concern 
the Aegean area and must have taken place when southern Greece, the Kythera, Antikythera, Crete, Karpathos, Kassos and Rhodes as well as Asian Turkey were connected to each other through the Hellenic Arc. This event occurred at least twice: during the Miocene (from 23 to 12 MYA) when the Aegean plate was not still submerged (Triantis and Mylonas 2009) and during the Messinian Salinity Crisis (from 5.9 to 5.3 MYA) when an isolated sea named "Egemar" was present in the north-eastern Aegean (Sakinç and Yaltirak 2005). The latter event only connected the islands located in the Hellenic Arc, which might explain why $S$. fruticosa is not found on any islands that are further north. A spatial expansion occurring at that time could explain why a unique haplotype is found in this area. An alternative explanation for the low number of haplotypes might be that the intraspecific polymorphism is underestimated in this study due to incomplete sampling, as only a few Mediterranean samples were available in the herbaria. It would be interesting, for instance, to genotype plants from Crete or Asian Turkey to confirm whether the same haplotype A35B24 is also present there. As for S. parad$o x a$, the most ancestral haplotype for the species was found in Greece and Cyprus, whereas the most distal one was found in Italy, indicating an east-to-west differentiation.

The two known populations of $S$. aristidis were genetically differentiated for both the chloroplast and nuclear markers. This clearly shows that the population from Constantine, which was only discovered in 1981 (Jeanmonod 1982), was not recently introduced, corroborating Jeanmonod's view. The gorges of Bin-Er-Redar close to Constantine cover a very small area, and the $S$. aristidis population is known there from one locality along the roadside. This most likely explains why there is only one haplotype for this small locality. Interestingly, S. aristidis showed similar measures of chloroplast gene and nucleotide diversities as $S$. italica, although it is an Algerian endemic found in two very restricted areas, whereas $S$. italica is a widely distributed taxon. The demographic expansion model was strongly rejected for S. aristidis, supporting a spatial expansion model that should have taken place before the species was restricted to two small areas. The proportion of heterogeneous genotypes for the nuclear markers was among the lowest recorded, probably due to extensive gene conversion and to the low effective population sizes of this narrow endemic species.

According to the chloroplast loci, Silene italica contains two distinct lineages. One covers the western part of the distribution range and groups individuals from France and Italy, whereas the other covers the eastern part with accessions from Greece, Turkey, Iran and eastern Italy. Silene italica went through a range expansion, a result that also fits the chloroplast network, showing few, but widely distributed haplotypes. Silene damboldtiana did not show any intraspecific variation for the chloroplast loci, despite the fact it has a wide distribution range. It did show intraspecific variation for ITS, and a high proportion of heterogenous genotypes $(77 \%)$ that might indicate recent speciation or hybridization events. Phylogeographic patterns for $S$. patula were discussed elsewhere (Naciri et al. 2010) and are compatible with a recent range expansion, specifically in Morocco, with the highest chloroplast diversity found in Algeria. The specific status of S. fernandezii is questionable because its unique haplotype (A9B9) and ITS variant (I99) are shared with $S$. mellifera. The former taxon might therefore be an ecotype (on serpentinite) of S. mellifera or might be the result of recent speciation. Silene mellifera has few haplotypes and ITS variants as well as moderate gene and nucleotides diversities that could reflect the moderate size of its distribution range. As for $S$. fruticosa or for $S$. patula, a spatial expansion scenario fitted the data better than a demographic expansion scenario. Genetic variation was extremely low for S. mollissima, which might reflect the limited range of the species (Mallorca and Minorca), or be due to the fact that the analysed samples came mainly from one population.

Gene and nucleotide diversities for the nuclear markers were generally higher in the italica complex than in the paradoxa group. Together with the shared ITS variants, it might indicate that the species of the italica complex went through recent speciation events, or have some ongoing interspecific gene flow, or both. This does not seem to be the case for the paradoxa group.

\section{Conclusions}

Based on the molecular analysis of one nuclear and two chloroplast markers, we showed that $S$. fruticosa, $S$. aristidis and $S$. paradoxa behave as distinct taxa. We also demonstrated that these three species form a distinct group within section Siphonomorpha, in agreement with the present morphology-based classification. S. paradoxa is likely to have undergone demographic expansion, whereas the two chasmophytes $S$. aristidis and $S$. fruticosa most probably followed a spatial expansion scenario. The chasmophytes and open rocky habitat species are found in both the paradoxa group and the italica complex, indicating that the switch between chasmophytic and open rocky habitats occurred at least twice in section Siphonomorpha.

Acknowledgments We wish to thank Régine Niba and Fadil Avdija (laboratory work), André Schlüssel, Camille Christe, Manuela Esmerode (sampling in Greece), Josep Lluis Gradaille (sampling in Mallorca) and Matthias Baltisberger (ZT herbarium specimens, study advisor of M.L.) for their help and Michelle Price for her revision of the English language. This study was supported by the CJB (financial 
support to M.L.), the Swiss Federal Institute of Technology Zurich (mobility grant to M.L.), the Fondation Claraz (grant for laboratory work to Y.N.) and the Société de Physique et d'Histoire Naturelle (Augustin Lombard travel fund to PEDP).

\section{References}

Àlvarez I, Wendel JF (2003) Ribosomal ITS sequences and plant phylogenetic inference. Mol Phylogenet Evol 29(3):417-434. doi:10.1016/S1055-7903(03)00208-2

Avise JC (2009) Phylogeography: retrospect and prospect. J Biogeogr 36:3-15

Bandelt HJ, Forster P, Rohl A (1999) Median-joining networks for inferring intraspecific phylogenies. Mol Biol Evol 16(1): $37-48$

Barriel V (1994) Phylogénies moléculaires et insertions-délétions de nucléotides (Molecular phylogenies and how to code insertion/ deletion events). C R Acad Sci Paris 317:693-701

Birky CW (2008) Uniparental inheritance of organelle genes. Curr Biol 18(16):R692-R695. doi:10.1016/j.cub.2008.06.049

Chater AO, Walters SM, Akeyrod JR (1993) Silene L. In: Tutin TG, Burges NA, Chater AO et al. (eds) Flora europaea, vol 1. 2nd edn. University Press, Cambridge, pp 191-218

Chowdhuri PK (1957) Studies in the genus Silene. Notes of the Royal Botanic Gardens Edinburgh 22(3):221-278

De Queiroz K (2007) Species concepts and species delimitation. Syst Biol 56:879-886

Doyle JJ, Doyle JL (1987) A rapid DNA isolation procedure for small quantities of fresh leaf tissue. Phytochem Bull 19(1):11-15

Excoffier L, Lischer HEL (2010) Arlequin suite ver 3.5: a new series of programs to perform population genetics analyses under Linux and Windows. Mol Ecol Resour 10(3):564-567. doi:10. 1111/j.1755-0998.2010.02847.x

Excoffier L, Laval G, Schneider S (2005) Arlequin (version 3.0): an integrated software package for population genetics data analysis. Evol Bioinform 1:47-50

Frajman B, Oxelman B (2007) Reticulate phylogenetics and phytogeographical structure of Heliosperma (Sileneae, Caryophyllaceae) inferred from chloroplast and nuclear DNA sequences. Mol Phylogenet Evol 43(1):140-155. doi:10.1016/J.Ympev. 2006.11.003

Fu Y-X (1997) Statistical tests of neutrality of mutations against population growth, hitchhiking and background selection. Genetics 147(2):915-925

Gardes M, Bruns TD (1993) ITS primers with enhanced specificity for basidiomycetes-application to the identification of mycorrhizae and rusts. Mol Ecol 2(2):113-118

Greenberg AK, Donoghue MJ (2011) Molecular systematics and character evolution in Caryophyllaceae. Taxon 60(6):1637-1652

Greuter W (1995) Silene (Caryophyllaceae) in Greece-a subgeneric and sectional classification. Taxon 44(4):543-581

Greuter W (1997) Silene L. In: Strid A, Tan K (eds) Flora Hellenica, vol 1. Koeltz Scientific Books, Königstein

Grimm GW, Denk T (2010) The reticulate origin of modern plane trees (Platanus, Platanaceae): a nuclear marker puzzle. Taxon 59(1):134-147

Hall TA (1999) BioEdit: a user-friendly biological sequence alignment editor and analysis program for Windows 95/98/NT. Nucleic Acids Symp Ser 41:95-98

Hamilton MB (1999) Four primer pairs for the amplification of chloroplast intergenic regions with intraspecific variation. Mol Ecol 8(3):521-523
Ingvarsson PK, Ribstein S, Taylor DR (2003) Molecular evolution of insertions and deletion in the chloroplast genome of Silene. Mol Biol Evol 20(11):1737-1740. doi:10.1093/Molbev/Msg163

Jalas J, Suominen J (eds) (1986) Atlas florae Europaeae, distribution of vascular plants in Europe: 7. Caryophyllaceae (Silenoideae), Helsinki, p 229

Jeanmonod D (1982) Nouvelle station du Silene aristidis Pomel en Algérie. Candollea 37:485-495

Jeanmonod D (1984) Révision de la section Siphonomorpha Otth du genre Silene L. (Caryophyllaceae) en Méditerranée occidentale. II: le groupe du S. mollissima (Revision of the section Siphonomorpha Otth of the genus Silene L. (Caryophyllaceae) on the Western Mediterranean area. II: the $S$. mollissima group). Candollea 39(1):195-259

Jeanmonod D (1985a) Révision de la section Siphonomorpha Otth du genre Silene L. (Caryophyllaceae) en Méditerranée occidentale. IV: species caeterae (Revision of the section Siphonomorpha Otth of the genus Silene L. (Caryophyllaceae) on the Western Mediterranean area. IV: species caeterae). Candollea 40:5-34

Jeanmonod D (1985b) Révision de la section Siphonomorpha Otth du genre Silene L. (Caryophyllaceae) en Méditerranée occidentale. V: synthèse. Candollea 40:35-56

Jeanmonod D, Mascherpa J-M (1982) Révision de la section Siphonomorpha Otth du genre Silene L. (Caryophyllaceae) en Méditerranée occidentale. Méthodes. Candollea 37:497-523

Klopfstein S, Currat M, Excoffier L (2006) The fate of mutations surfing on the wave of a range expansion. Mol Biol Evol 23(3):482-490

Manen JF, Barriera G, Loizeau PA, Naciri Y (2010) The history of extant Ilex species (Aquifoliaceae): Evidence of hybridization within a Miocene radiation. Mol Phylogenet Evol 57(3):961-977. doi:10.1016/J.Ympev.2010.09.006

Mengoni A, Barabesi C, Gonnelli C, Galardi F, Gabbrielli R, Bazzicalupo M (2001) Genetic diversity of heavy metal-tolerant populations in Silene paradoxa L. (Caryophyllaceae): a chloroplast microsatellite analysis. Mol Ecol 10(8):1909-1916. doi:10. 1046/j.0962-1083.2001.01336.x

Möller M, Cronk QCB (1997) Origin and relationships of Saintpaulia (Gesneriaceae) based on ribosomal DNA internal transcribed spacer (ITS) sequences. Am J Bot 84(7):956-965

Naciri Y, Gaudeul M (2007) Phylogeography of the endangered Eryngium alpinum L. (Apiaceae), in the European Alps. Mol Ecol 16:2721-2733

Naciri Y, Manen JF (2010) Potential DNA transfer from the chloroplast to the nucleus in Eryngium alpinum. Mol Ecol Resour 10(4):728-731. doi:10.1111/J.1755-0998.2009.02816.X

Naciri Y, Cavat F, Jeanmonod D (2010) Silene patula (Siphonomorpha, Caryophyllaceae) in North Africa: A test of colonisation routes using chloroplast markers. Mol Phylogenet Evol 54(3):922-932. doi:10.1016/J.Ympev.2009.11.015

Naciri Y, Caetano S, Salamin N (2012) Plant DNA barcodes and the influence of gene flow. Mol Ecol Resour 12(4):575-580. doi:10. 1111/J.1755-0998.2012.03130.X

Nei M (1987) Molecular evolutionary genetics. Columbia University Press, New York

Posada D, Crandall KA (2001) Intraspecific gene genealogies: trees grafting into networks. Trends Ecol Evol 16(1):37-45

Rautenberg A, Hathaway L, Oxelman B, Prentice HC (2010) Geographic and phylogenetic patterns in Silene section Melandrium (Caryophyllaceae) as inferred from chloroplast and nuclear DNA sequences. Mol Phylogenet Evol 57(3):978-991. doi:10. 1016/j.ympev.2010.08.003

Roberts BA, Proctor J (1992) The Ecology of Areas with Serpentinzed Rocks: a world View. Kluwer, Dordrecht 
Sakinç M, Yaltirak C (2005) Messinian crisis: what happened around the northeastern Aegean? Mar Geol 221:423-436

Stephens M, Smith N, Donelly P (2001) A new statistical method for haplotype reconstruction from population data. Am J Hum Genet 68:978-989

Tajima F (1983) Evolutionary relationship of DNA sequences in finite populations. Genetics 105(2):437-460
Tajima F (1993) Measurement of DNA polymorphism. In: Takahata N, Clark AG (eds) Mechanisms of molecular evolution: introduction to molecular paleopopulation biology. Japan Scientific Soc Press, Tokyo, pp 37-59

Triantis KA, Mylonas M (2009) Greek islands, biology. In: Gillespie RG, Clague DA (eds) Encyclopedia of islands. University of California Press, Berkeley, pp 388-389 